\title{
Dominio de mercado y precios "abusivos"
}

¿Qué es un precio abusivo? Economistas y abogados llevan años discutiendo este tema, sobre todo en casos relacionados con defensa de la libre competencia. No siempre están de acuerdo.

Por Julio Peña Torres*

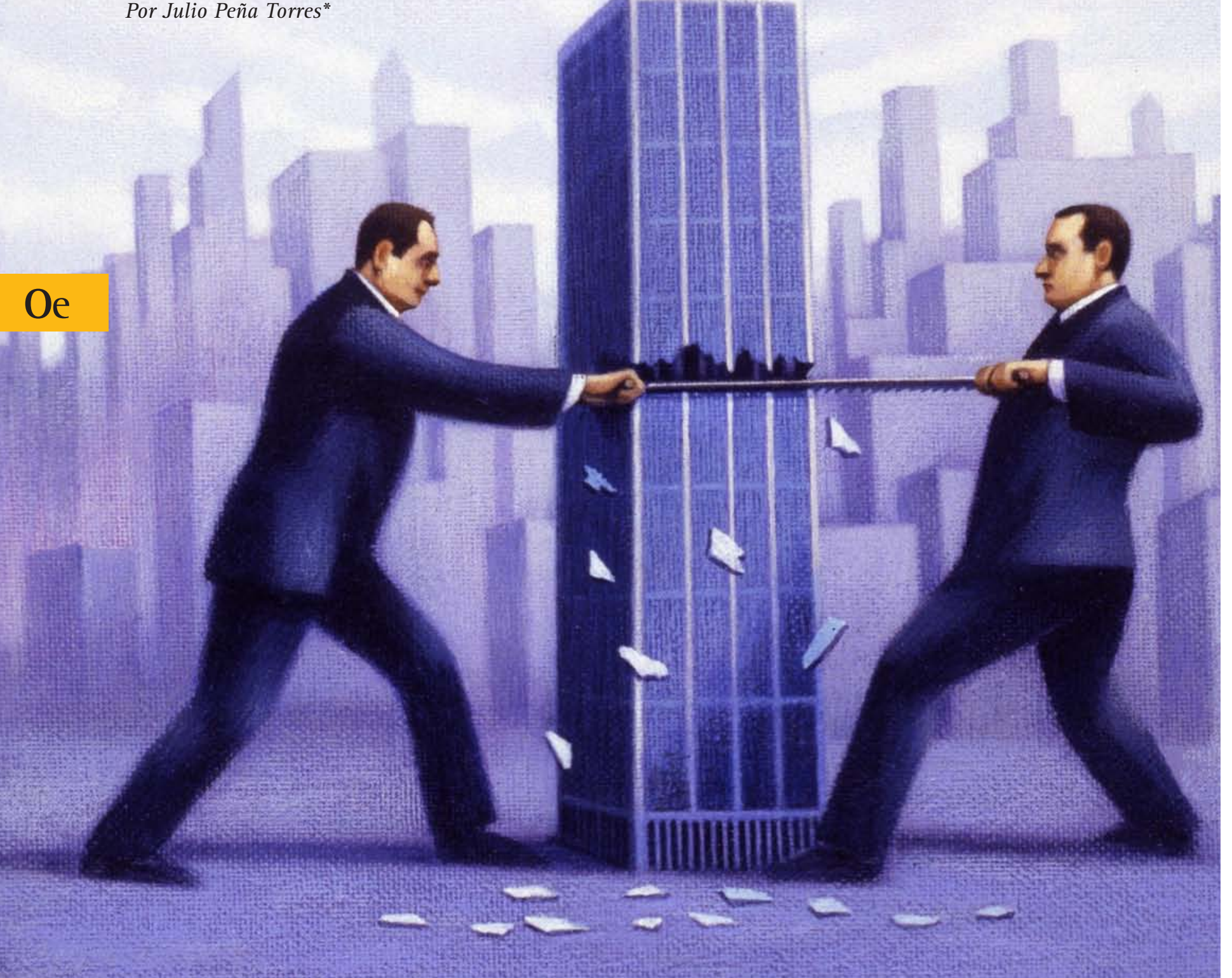

No debiera sorprender que debates so- ridico "defensa de la libre competencia", bre concentración economica, dominio de a lo que nos referimos, en palabras muy mercado y eventuales abusos" o ilicitos simples, es a un ambito de ley que busa apasianos a su ejercicio puedan producir ca salvaguardar que la competencia en pasionamiento en el ciudadano de la calle. Pero si sorprende que dos profesiones con especialistas en estos temas, como son los abogados y economistas, no siempre compartan los mismos significados para
ceptos claves en estas discusiones.

Por esto útimo $y$ dada la importanca pública de la práctica juridica en temas de libre competencia, en esta nota intentamos aunar significados entre el mundo jurídico y el económico, para entender mejo un par de conceptos claves relativos al siguiente dilema de política pública: ¿cuándo el precio cobrado por una empresa con "posición de dominio de mercado" pued entenderse como abusivo, en el sentido de ser ilicito desde el punto de vista de bien juridico de "defensa de la libre competencia"?

Partamos con un par de aclaraciones básicas

Primero. Lo que el mundo juridico llama "posición de dominio de mercado" en clara o inambigua y por lo mismo podrí asociarse con distintos significados, pero en rigor es equivalente a lo que en economía se denomina "poder de mercado", es decir, la capacidad de imponer las condiciones del intercambio con prescindencia en un grado apreciable, de competidores consumidores.

Segundo. Cuando se habla del bien ju- los mercados ocurra "en buena y sana lid", esto es, sin trampas, fraudes u otros aricior de mercado de quien los ejecuta, dañando con ello el bienestar colectivo de los agentes económicos que participan en esos mercados (y no solo el de los particulares directamente involucrados en una determinada transac

Para simplificar, analicemos solo el caso de la fijación unilateral (esto es, no colusiva) de precios "abusivos" por parte de un . donde exista libertad para definir el precio del intercambio (no nos referitemos a preto a regulación tarifaria). DOCTRINA Y PRÁCTICA JURIDICA La ley chilena de defensa de la libre competencia (DL 21) establece en su articulo 3 de posición dominante: "Se considerarán ciones que impiden, restringen o entorpecen la libre competencia o que tienden a producir dichos efectos, los siguientes: b) La explotación abusiva por parte de un agente económico, o un conjunto de ellos de una posición dominante en el mercado, fijando precios de compra o de venta, imponiendo a una venta la de otro producto, asignando zonas o cuotas de mercado o entre otros, como hechos actos o conven- noniendo a otros abusos semejantes". si llevamos la doctrina juridica a su sencia, existen dos vertientes conceptuales para definir to que se entiende po "abuso de dominio de mercado. Una de"abuso" de domiro de mencalo. Un ilicito la para haber do la conducta. En ella, par conducta sea apta para adquiriti, mantener mercado. Se requiere además que dicho recto. de (que haya tenido por "objeto") lograrlo mediante una conducta "abusiva" (es decir, un fraude, astucia, barrera artificial discriminación arbitraria que sea apta para distorsionar la libre competencia). Lo anterior, en oposición a lograr dominio de mercado en base al merito (por ser mas eficiente, sea por propia iniciativa o por hecho fortuito.

Esta es la doctrina que, con distintos enfasis a través del tiempo, ha prevalecido veonthua hoy vigente en EE.U. En esta si solo, el nivel del precio transado, por sis existe dominio de mercado, un precio ex́ "abusiv" sole si se turo, por objeto alcanzar dicho precio mediante una conducta distorsionadora de la libre competencia (y que sea responsabilidad de ejecutor). En una sentencia reciente (n 3/2010), el Tribunal chileno de Defens de la Libre Competencia ha adscrito a esta Inea doctrinal (para analisis al respecto, éase Menchaca 2011).

La otra vertiente conceptual sobre pre- 
cios "abusivos" o "excesivos" proviene de la legislación europea sobre ilicitos antifocada a una doctrina de "efectos". En ella no sería requisito esencial, ciertamente no con los estándares de prueba exigidos por la doctrina en USA, juzgar conceptos subjetivos como la intencionalidad anticompetitiva (el "objeto" o la "voluntad" detrás de la acción). Ello por cuanto el "abuso de posición dominante" sería un concepto objetivable, basado en criterios que de-

competencia (Vickers, 2008).

TERPRETACIÓN ECONÓMICA

El requisito de intencionalidad
dos consecuencias de fondo.

Primero, exige formarse convicción de que existe una relación causal inequivo entre conducta y poder de mercado. La doctrina europea, más directamente basa da en acreditar el "efecto anticompetitivo impone eständares más laxos que la estadounidense respecto a la naturaleza de esa relación causal. Assi, con el requisito de intencionalidad, contextos de competencia que puedan derivar en múltiples equilibrios de mercado (esto es, en múltiples posibes "efectos") mplicaran una mayor exigencia de prueba para acredi

conducta causal seria "abusiva". Esto implica responder preguntas como imediante qué medios (licitos o ilicitos) se obtien el dominio de mercado? Desde el punto de vista de la teoría económica, esto implica entender las fuentes de tal dominio. Pero además requiere criterios claros que delimiten la licitud o no del medio usado pa competir. Algunos criterios son evidentes: ganar mediante fraude o trampa intencional debiera ser ilícito. Lo mismo mediante praccticas que tr vigente.

Pero existen casos menos obvios. Por ejemplo, si existe la aptitud para alcanzar mantener o inerementar una posición de cominio de mercado, se suele considerar sición de una barrera "artificial" a la entrada o expansión de firmas rivales. joue criterio permitiría entonces discriminar entre una barrera "natural" (licita) y una "Podrim (is definir

"Pusu" a todo medio "natural" o "no que, sin transgredir norma legal tampoco genere daño en términos de algún indicador consensuado de bienestar social. Supongamos que ese indicador general corresponde a efectos sobre la "eficiencia economica" del intercambio, entendiendo lumen de transacciones que maximiza la creación de valor económico a partir del
intercambio (por falta de espacio, no puedo aquí discutir posibles variantes de esta do aquí dis
definición).

Con un criterio de este tipo se obtiene Con un criterio de este tipo se obtiene
una métrica objetiva de los "efectos" que tos anticompetitivos. Si una conducta es apta para mantener o fortalecer dominio de mercado, y para lograrlo se reduce la "eficiencia económica" en ese mercado, entonces esa conducta será abusiva.

Persiste el tema del horizonte temporal en el cual evaluar los efectos sobre el indicador de bienestar social. Al respecto, surgen preguntas como ¿qué se ha hecho. se planea hacer, con las rentas obtenidas acias al dominio de mercado? Es evidenque la respuesta afectará al valor de la en un ejemplo obvio: la entrega del derecho (monopólico) de patente a innovadores exitosos, bajo la justificación de que procanismo de protección de rentas proveerá los incentivos necesarios para acometer los costos y riesgos inherentes esfuerzo innovador. Este tipo de análisis traturalmente requiere evaluar efectos a (t) conviene definir caso a caso. Concluy: En esta nota he pla

Contanteado cosición dominante" que permite abuso as respectivas lecturas conceptuales del. mundo jurídico y del económico. Con esta nterpretación, los economistas podemos ayudar a avanzar hacia una legislación pro-competencia mas justa y eficiente. Pero ello requiere producir doctrinas que sean robustas y que encuentren usos pracicables en las decisiones de las agencias estatales y los tribunales pro-competencia. Solo asi se contribuirá a crear mayor

T. Menchaca (2011), ¿Se debe sancionar la en La Libre Competencia en el Chile del Bicentenario, TDLC (ed.), Thomson Reuters, Stgo.-Chile (por aparecer)

Vickers (2008), Abuse of market power,
cap. 11 en P. Buccirossi (ed), Handbooks cap. 11 en P. Buccirossi (ed.), Handbook
of Antitrust Economics, The MIT Press, London.

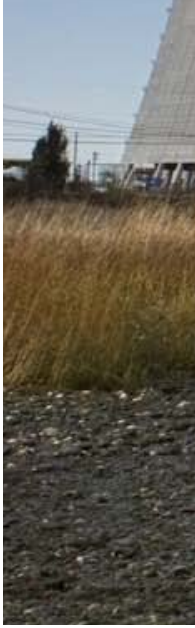

Energía nuclear: ¿Cómo conducir un debate constructivo? Por Alfredo del Valle

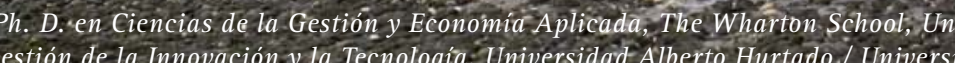

El terremoto y el tsunami del 11 de marzo en Japón abrieron el flanco de la segu-
ridad sismica en el debate nuclear: si un pais sismico tan avanzado está viviendo la pais sismico tan avanzado está viviendo
tragedia actual, ¿tiene sentido que Chile se arriesgue a lo mismo, con menos capaciarriesgue a $10 \mathrm{~m}$ is
dades y recursos?

Mientras Japón hacía heroicos esfuerzos por mitigar el desastre, la prensa chilena mostraba a partidarios y opositores con las mismas posiciones de siempre. El caso Fukushima demostraría que: (1) no se debe nuclearizar el pais, o (2) se debe aprender de él porque esta tecnologia sigue siendo necesaria. Era un diálogo de sordos. Chile requiere y merece otro tipo de debate para secuencias de muy largo plazo y que no tiesecuencias de muy
ne vuelta atrás.

ne vuelta atrás.

Examinemos primero el contexto global de este debate, que lleva décadas abierto. resultos "El articulo respectivo de Wikipedia (con neutralidad bajo disputa) contiene 111 referencias a trabajos cientificos y profesionales junto a cientos de enlaces a otras páginas suyas, así como a sitios de partidarios y de opositores. Hay un vasto debate global en que confluyen numerosos actores con sus intereses, infinidad de temas, las más variadas disciplinas técnicas y sociales. asi como diferentes visiones del mundo: empresariales, ambientalistas, cientificas, profesionales, politicas, ciudadanas. Todo un problema de "alta complejidad"

¿Cómo debatir en Chile un problema esta naturaleza? ¿Cómo iluminar una decisión de pais para que tenga seriedad y coherencia, y que logre respaldo y no genere la complejidad ofrecen hoy dia una respuesta clara: solo habrá debate constructivo si se permite la expresión libre de toda la riqueza y diversidad temática del problema, y se evita la imposición de cualquier simdebate con estas caracteristicas es preciso diseñarlo de modo explícito y cuidadoso. Ofrecemos a continuación algunas bases de diseño que cumplen con los criterios recién planteados. Se refieren a la convocatoria al .

En la convocatoria se abordan tres preca? ¿A quiénes convoca? Quienes a este debate serán responsables de crear condiciones de credibilidad, imparcialidad y cobertura temática que lo hagan aceptable para los convocados y que faciliten su legitimación social; nuestra práctica aconseja constituir un "grupo convocante" de varios actores claves. El temario o agenda de la convocatoria debe ser amplio y sin estricciones. Y los convocados, personas e dos criterios: que en su conjunto cumplan representatividad del espectro completo de resesest visidad del espectro completo de qui confluyen. El proceso debe ser: (a) constructivo visión del problema que sea compartida, ultidimensional y de suficiente riqueza para que exprese toda su compleijidad; (b) equilibrado ante todas las opciones energeticas que el pais posee, (c) sin sesgos avor ni en contra de la energia nuclear; (d) inclusivo para todos los costos y beneficios drectos e indirectos; y (e) inclusivo para todos los avances tecnológicos previsibles. costos de las demas opcior como en los costos de las demás opeione En Chile no tenents

- tenemos todavía un debate

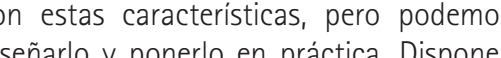
nos además de métodos probados para ograrlo.

Decervatorio Jorge Rodrímico \} Fono Facultad: 8897366 Quahurtado.cl - conomiaynegocios.uahurtado.cl/observatorio
Producción OE: Comunicar. Escuela de Periodismo UAH. 